\title{
Moment tensor solutions for the Amatrice 2016 seismic sequence
}

\author{
SILVIA PONDRELli*, SimONe SALIMBENI, PAOLO PERFETTI \\ Istituto Nazionale di Geofisica e Vulcanologia, Sezione di Bologna, Italy \\ *silvia.pondrelli@ingv.it
}

\begin{abstract}
On August 24, 2016 a $M_{L} 6.0$ earthquake struck central Italy region, nearly completely destroying some small ancient towns as Amatrice, Accumoli, Arquata and Pescara del Tronto. In the following days thousands of aftershocks have been recorded by the INGV National Seismometric Network, 16 of them with a magnitude greater than 4.0. A Quick RCMT solution has been rapidly computed for all of them and made available on the web. Within a few weeks a definitive RCMT solution is ready for all of them, plus one. For major events (and not only) of the Amatrice seismic sequence, several rapid moment tensor solutions have been produced by various groups, using different methods and dataset. Comparing QRCMTs with other similar products, it is evident a great similarity of focal mechanisms while on the contrary, the Mw have a clear variability.
\end{abstract}

\section{INTRODUCTION}

$\mathrm{W}$ hen an earthquake occurs with a magnitude greater than 4.5 in the EuroMediterranean region, in a short time, between minutes to hours, several moment tensors are made available. Among them, the Quick RCMT (Regional Centroid Moment Tensor; Pondrelli et al., 2012) is computed automatically, revised by an operator and then pubblished on the dedicated web page (autorcmt.bo.ingv.it/quicks. html) and on the European Mediterranean Seismological Center (EMSC) event web page (www.emsc-csem.org). This preliminary semiautomatic procedure, named pypaver, is applied since 2010 (Pondrelli et al., 2012) and after several years of test, also in this last seismic emergency has properly worked. In fact, the 24 of August 2016 at 1:36 am, when a $\mathrm{M}_{\mathrm{L}} 6.0$ earthquake struck powerfully Amatrice and other small towns of Central Italy, a Quick RCMT (QRCMT) has been rapidly computed and made available. The automatic procedure has been activated by an INGV email alert including the preliminary hypocentral location.
The same process activated several times in the following hours and days, allowing the computations of a ten of QRCMTs (Figure 1 and Table 1; http:/ / autorcmt.bo.ingv.it/quicks. html). Out of seismic sequences, after 3-4 months the QRCMTs have been determined, a revision is done, using the largest amount of seismograms available. Then, a definitive RCMT solution is obtained and included in the European Mediterranean RCMT Catalog (Pondrelli et al., 2015 and references therein; www.bo.ingv.it/RCMT/). Definitive RCMT solutions for greater events of the Amatrice seismic sequence have been computed rapidly, within one month from the main shock (Figure 1). RCMTs, quick and definitive, are computed using an inversion method derived from the Global CMT computation method (Ardvisson and Ekström, 1998; Ekström and Nettles, 2014; Ekström et al., 2012), that calculates synthetic and inverts seismograms for body and surface waves recorded mainly (but not only) at regional distances and at intermediate period, i.e. between 35 and $150 \mathrm{~s}$ (Pondrelli et al., 2015). In this brief paper, we will report on the comparison between QRCMTs, 


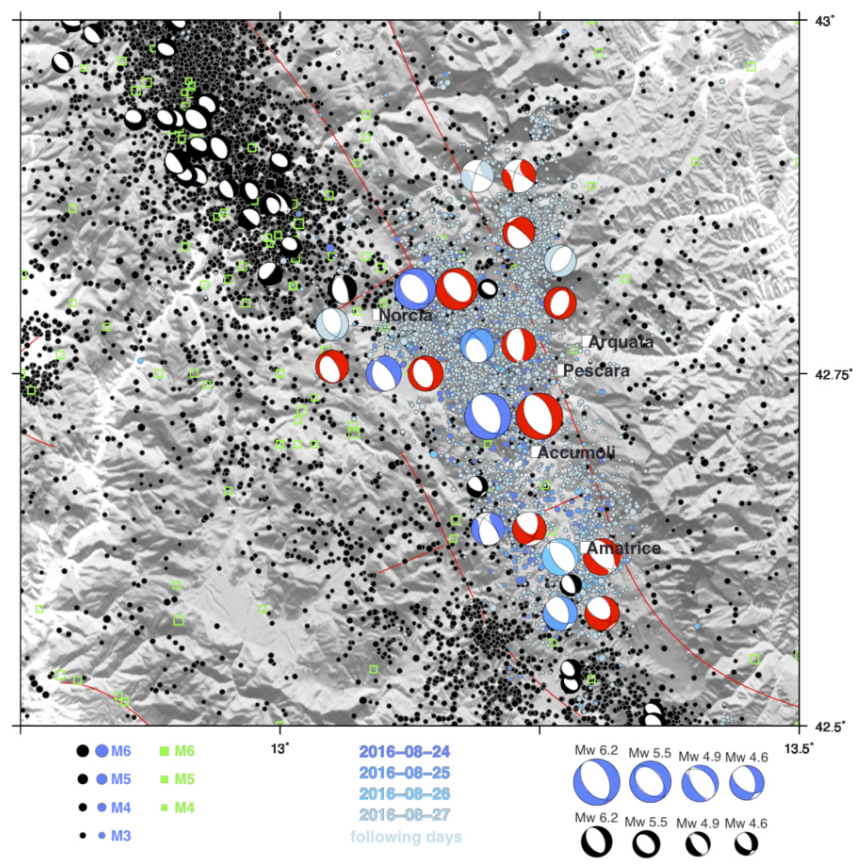

Figure 1. Map of seismicity, QRCMTs and RCMTs of the Amatrice region. QRCMTs are in blue to light blue (different shades are for different days of occurrence, following the label below the map), revised RCMTs are in red. In black are focal mechanisms for previous earthquakes with $M>4.0$ (European-Mediterranean RCMT Catalog, http://www.bo.ingv. it/ RCMT). Green squares are historical events, scaled with magnitude (Rovida et al., 2016; http://emidius.mi.ingv.it/CPTI15). Background seismicity is mapped with black circles for events before Amatrice main shock, while in different blue shades are mapped events of the Amatrice seismic sequence (M>2.0, ISIDE WG, 2016; http://iside.rm.ingv.it/iside/standard/index.jsp).

\begin{tabular}{cccccccc} 
Date & Time & Lat. & Long. & $\begin{array}{c}\text { Depth } \\
(\mathrm{km})\end{array}$ & ML & $\begin{array}{c}\text { Mw } \\
\text { QRCMT }\end{array}$ & Mw final RCMT \\
\hline $2016-08-24$ & $01: 36: 32$ & 42.698 & 13.234 & 8.1 & 6.0 & 6.20 & $\begin{array}{c}6.21(\mathrm{bw}) \\
6.20(\mathrm{sw}) \\
\end{array}$ \\
& & & & & & & 6.18 (comb.) \\
\hline $2016-08-24$ & $01: 37: 26$ & 42.712 & 13.253 & 9.0 & 4.5 & --- & --- \\
\hline $2016-08-24$ & $01: 56: 00$ & 42.614 & 13.275 & 4.8 & 4.4 & --- & --- \\
\hline $2016-08-24$ & $02: 33: 29$ & 42.794 & 13.154 & 8.7 & 5.4 & 5.52 & 5.54 \\
\hline $2016-08-24$ & $03: 40: 11$ & 42.617 & 13.245 & 10.6 & 4.2 & --- & --- \\
\hline $2016-08-24$ & $04: 06: 50$ & 42.769 & 13.125 & 7.6 & 4.3 & 4.74 & --- \\
\hline $2016-08-24$ & $11: 50: 30$ & 42.819 & 13.146 & 8.4 & 4.7 & -- & 4.49 \\
\hline $2016-08-24$ & $17: 46: 09$ & 42.663 & 13.222 & 10.0 & 4.4 & 4.39 & --- \\
\hline $2016-08-24$ & $23: 22: 05$ & 42.648 & 13.213 & 11.2 & 3.8 & -- & 4.58 \\
\hline $2016-08-25$ & $03: 17: 16$ & 42.753 & 13.208 & 9.5 & 4.5 & 4.63 & 4.60 \\
\hline $2016-08-25$ & $12: 36: 05$ & 42.596 & 13.290 & 10.0 & 4.3 & 4.60 & 4.94 \\
\hline $2016-08-26$ & $04: 28: 25$ & 42.600 & 13.290 & 10.9 & 4.8 & 4.93 & 4.31 \\
\hline $2016-08-27$ & $02: 50: 59$ & 42.839 & 13.249 & 8.2 & 4.0 & --- & 4.32 \\
\hline $2016-08-28$ & $15: 55: 35$ & 42.820 & 13.238 & 8.7 & 4.4 & 4.30 & 4.44 \\
\hline $2016-09-03$ & $01: 34: 12$ & 42.775 & 13.130 & 10.6 & 4.3 & 4.38 & 4.48 \\
\hline $2016-09-03$ & $10: 18: 51$ & 42.866 & 13.215 & 9.3 & 4.5 & 4.46 & \\
\hline
\end{tabular}

Table 1. List of events for which a trial to compute a QRCMT has been done. Locations and ML are from INGV CNT first determination (cnt.rm.ingv.it), Mw QRCMT are from autorcmt.bo.ingv.it/quicks.html and Mw RCMT are for revised solution from this paper. Different values for Mw of the main shock are from the inversion for different signals: bw - only body waves; sw - only surface waves; comb. - body and surface waves combined. 
revised RCMTs and other rapid moment tensor solutions for the same group of events.

\section{QUICK AND DEFINITIVE RCMTS}

As already described, immediately after the earthquake of the August 24, a QRCMT solution has been determined, and the same has been tried for all events with a ML 4.0. In Table 1 the list of the events for which a trial to compute a rapid solution has been done, shows that we obtained a results in 10 over 16 cases. Most of failed attempts are in the few hours after the main shock, when signal of minor events, i.e. $M$ between 4 and 4.5, is completely hidden by the coda of the M6 earthquake. Only few hours after the main shock it has been possible again to compute a QRCMT with M 4.2. The ten QRCMTs are drawn in Figure 1. They show a prevailing extensional pattern, as commonly seen along the Apennines, with a tensional direction NE-SW. A couple of focal mechanisms are slightly different. One, located in the NEastern part of the aftershocks cloud, is still extensional but rotated nearly $90^{\circ}$ with respect to others; another one, again located at NE shows a strike-slip focal solution. Being smaller events, they probably nucleated along secondary faults, with different geometry with respect to the principal NE-SW extensional activated structure.

Definitive RCMTs, computed after one month, are either shown in Figure 1 (red focal mechanisms). One more solution is avaliable with respect to QRCMTs, due to additional seismograms available later. In Table $1, \mathrm{Mw}$ for definitive RCMT solutions are reported, showing a good agreement with values obtained for QRCMTs and focal mechanisms are almost identical (Figure 1). A small no-DC component affects some solutions, mainly QRCMTs; however it is a common amount, overall during a seismic sequence, where the continuous seismicity makes seismograms often more noisy. An additional test has been done during revision. For the main shock of August 24, we computed several RCMT solutions: one invert- ing only for body waves, another one using just surface waves and, at the end, a combined solution with both waveforms (see Figure in Supplementary files). All of them gave a pure, extensional focal mechanism, identical in all three cases. In Table 1 we included all three values obtained for the $\mathrm{Mw}$, to show we obtain always the same value, Mw 6.2.

\section{COMPARISON WITH OTHER QUICK SOLUTIONS}

In Figure 2, all QRCMTs computed immediately after the occurrence of events belonging to the Amatrice seismic sequence are drawn in the first colum, together with other rapid moment tensor solutions we were able to find, computed for the same events by other agencies and using other techniques. This figure allows a visual comparison. A description of data we compare with QRCMTs follows.

USGS moment tensor solutions are reachable at the event page of any single event (earthquake. usgs.gov/earthquakes) or in the web pages of the archive (http: / / earthquake.usgs.gov / earth quakes/eventpage/us10006g7d\#moment-tensor). USGS moment tensors are computed for earthquakes with $\mathrm{M}$ down to 4.0, when possible. For greater events, solutions are obtained inverting the W-phase, a very long period phase (between 100 and $1000 \mathrm{~s}$ ) arriving with the P-wave, well visible on vertical component of broadband displacement records. The computation method is well described at http:/ / eost.ustrasbg.fr/wphase / method.html.

These moment tensor solutions can be computed at both regional (5 to 20 degrees) and, more often, at teleseismic distances. In these cases, the $\mathrm{Mw}$ reported is Mww. It is worth to note that for smaller magnitude events, moment tensors come from inversion of the complete waveforms at regional distances (less than $\sim 13$ degrees) and the $\mathrm{Mw}$ is then named Mwr (earthquake.usgs. gov/data / comcat/dataeventterms.php\#magT ype). It is worth to note that in the USGS list of the Amatrice seismic sequence, all events with M lower than 5.0 have an Mwr only. 


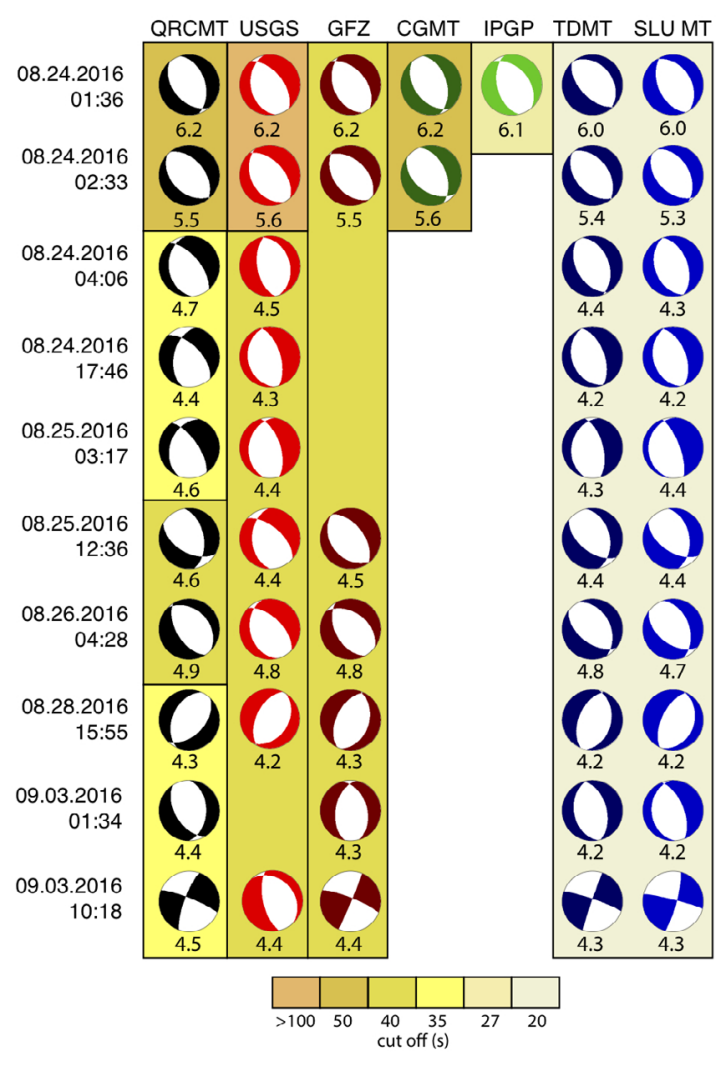

Figure 2. In the first colum, Quick RCMTs computed for 10 events of the Amatrice seismic sequence. On the left, date and time of the earthquakes. Other columns are the other rapid focal mechanisms available; for references see the text. The color in the background represents the different cut off values used in each computation methods.

Solutions reported as GFZ are computed at the German Research Centre for Geoscience and are reachable at the following link: geofon.gfzpotsdam.de/ eqinfo/list.php? mode $=\mathrm{mt}$. They are obtained for events also with small to moderate magnitudes, with an automatic procedure, applying a spectral analysis technique that, to reach the best fitting source parameters, adopts the appropriate range of phases, frequency and inversion method along computations (Saul et al., 2011). For events of the Amatrice sequence, being at an epicentral distance greater than $200 \mathrm{~km}$, applied bandpass filters should be 0.01-0.025.

GCMT, the Global CMT focal mechanisms, are the most used and diffused solutions. The entire catalog is searchable at http: / / www. global cmt.org. Usually CMT solutions are computed for events with $M$ greater than 5, and this is the reason of the only two CMTs displayed in Figure 2. The computational method is extendedly described in Ekström and Nettles (2014).

The unique IPGP solution comes from the SCARDEC project, active at Geoscope Observatory (geoscope.ipgp.fr/index.php/en/data/ earthquake-data/latest-earthquakes).

The SCARDEC method uses teleseismic body waves (in particular the $\mathrm{W}$-phase) to retrieve the source parameters of earthquakes with magnitudes larger than 5.5 - 6.0 (Vallée et al., 2011). The highpass frequency is dependent on the earthquake magnitude and duration, ranging from $0.0125 \mathrm{~Hz}$ for a M 6 to $0.003 \mathrm{~Hz}$ for a very large and long earthquake.

TDMT solutions are reachable at cnt.rm.ingv.it/ tdmt. These moment tensors are computed first automatically and then reviewed, for any event with ML greater than 3.5 occurred in Italy. The inversion method is an evolution of the Dreger and Helmberger (1993) system and changes applied to it are described in Scognamiglio et al. (2009).

SLU MT solutions are computed at the Saint Louis University, using codes described in Herrmann (2013), and can be downloaded at www.eas.slu. edu/eqc/eqc_mt/MECH.IT, where source parameters for Italy events in particular are stored. The TDMT and SLU MT have in common the crustal velocity model, named CIA (Herrmann et al., 2011) and typical frequency interval of analysed signal, i.e. 15-40 $\mathrm{s}$, the shortest if compared to others methods listed here.

At first sight, in Figure 2, a strong correspondence between all focal mechanisms solutions for all events exists, except for few small differences, as for the event of September 3, 10:18 for which USGS obtained an extensional mechanism when all other solutions are strike slip. What is less homogeneous is the Mw value obtained by different methods (Figure 2 and Table 1). 


\section{DISCUSSION}

Several rapid moment tensor solutions are computed immediately worldwide after the occurrence of a strong earthquake. In the Amatrice case, we compared the results obtained with different methods of computation, for 10 events of the sequence, all with $\mathrm{M}$ greater than 4.0. Focal mechanisms are in general strongly similar except for a couple of solutions (Figure 2). What clearly differs is the Mw, thus the M0 seismic moment. In particular, it is possible to recognize two main families of seismic moment tensors, one produced using global or regional velocity models and long period seismograms (CMT s.l., USGS, IPGP, Figure 2), the other includes solutions computed using local velocity models (i.e., CIA, Herrmann et al., 2011) and higher frequency signals (TDMT and SLU MT). USGS moment tensors are a particular case because obtained with different methods depending on their magnitude: the main shock and the events with $\mathrm{M}$ greater than 5 have been elaborated using the $\mathrm{W}$-phase method, while the other events using a regional method. A similar situation exists for GFZ solutions for which usually the cut off changes with $\mathrm{M}$; the declared bandpass filter here is $0.01-0.025 \mathrm{~Hz}$ for all solutions (Figure 2, the same color background is used for GFZ), but we can also assume that for greater events the cut off may increase. Therefore, we consider that USGS and GFZ part of solutions belongs to one family and another part to the other.

In general, looking to Figure 2, we can say that Mw values for the "long period" family are equal for great earthquakes and bigger than values given by "shorter period" families. To enhance this pattern, a different background color has been used, scaled with lower period of signal used for inversion. It seems like a local Mw exists, determined using "shorter period" methods; it is in relation with the calibrated worldwide $\mathrm{Mw}$ with a constant difference of -0.2 , as described by Gasperini et al. (2013). Up to now, this difference is still motivated with the difference in methodologies or in the dataset of used seismograms. However, it is worth to note that these differences exist also among RCMT and GFZ or USGS results, that actually produce the same value for $\mathrm{Mw}$. What make really the difference between what applied by the two groups is the frequency of inverted signal and, consequently, the velocity models. For instance, the velocity model used by TDMT and SLU MT is a crustal model, while long period methods need regional to global propagation models. This interesting feature points also the attention on the choice of the Mw to use when we include the data in a Cata$\log$ or in any seismic hazard study. At present, solutions like RCMTs are preferred because calibrated with past data, ensuring the homogeneity needed in a Catalog. For instance, this characteristic avoids underestimations in seismic hazard evaluations. However, being high frequency techniques, as TDMT and SLU MT, able to find out good quality source parameters for smaller events (e.g. M 3.5), assume a fundamental relevance in seismotectonic studies, where also minor events may reveal information otherwise not available. In conclusion, it can be useful to include in Catalogs all these values for the $\mathrm{Mw}$, with indications of the used bandpass filter, to fix if they can be cosidered local, regional or worldwide magnitude. Obviously, to test the hypothesis exposed here for the different value that $\mathrm{Mw}$ has dependently on methods and signals used, a larger dataset for the comparison is necessary to have a statistic validity, and it is what we suppose to do in the next future.

\section{ACKNOWLEDGEMENTS}

We would like to thank the anonymous reviewer for interesting suggestions and F. Loddo for help given in the download of data.

\section{REFERENCES}

[Arvidsson and Ekström, 1998] Arvidsson, R., Ekström, G., 1998. Global CMT analysis of moderate earthquakes $\mathrm{MW} \geq 4.5$ using inter- 
mediate period surface waves. Bull. Seismol. Soc. Am. 88, 1003-1013.

[Dreger and Helmberger, 1993] Dreger, D. S., and D. V. Helmberger (1993), Determination of Source Parameters at Regional Distances with Single Station or Sparse Network Data, Journ. Geophys. Res., 98, 8107-8125.

[Ekström and Nettles, 2014] Ekström, G., and Nettles, M. (2014). Long-Period Moment-Tensor Inversion: The Global CMT Project. In Encyclopedia of Earthquake Engineering, http: / / link. springer.com/ referenceworkentry / 10.1007/97 8-3-642-36197-5_291-1.

[Ekström et al., 2012] Ekström, G., Nettles, M. and Dziewonski, A. (2012). The global CMT project 2004-2010: Centroid-moment tensors for 13,017 earthquakes, Phys. Earth Plan. Int., 200-201, 1-9.

[Gasperini et al., 2013] Gasperini, P., Lolli, B., Vannucci, G. (2013). Empirical Calibration of Local Magnitude Data Sets Versus Moment Magnitude in Italy, Bull. Seism. Soci. Am., 103, 4, 2227-2246, doi: 10.1785/0120120356.

[Herrmann et al., 2011] Herrmann, R.B., Malagnini, L., and Munafò, I. (2011). Regional moment tensors of the 2009 L'Aquila earthquake sequence, Bull. Seism. Soc. Am. 101, 975-993. doi: $10.1785 / 0120100184$

[Herrmann, 2013] Herrmann, R.B. (2013) Computer programs in seismology: An evolving tool for instruction and research, Seism. Res. Lett., 84, 1081-1088, doi:10.1785/0220110096.

[ISIDe working group (2016)] ISIDe working group (2016), version 1.0, DOI: 10.13127 / ISIDe.

[Pondrelli et al., 2012] Pondrelli, S., Salimbeni, S., Perfetti, P., Danecek, P. (2012). Quick regional centroid moment tensor solutions for the Emilia 2012 (northern Italy) seismic sequence. Ann. Geophys., 55:4.
[Pondrelli et al., 2015] Pondrelli, S., and Salimbeni, S. (2015). Regional Moment Tensor Review: An Example from the European Mediterranean Region. In Encyclopedia of Earthquake Engineering, link.springer.com/ reference workentry/10.1007/978-3-642-36197-5_301-1, Springer Berlin Heidelberg, 1-15.

[Rovida et al., 2015] Rovida, A., Locati, M., Camassi, R., Lolli, B., Gasperini, P., eds. (2016). CPTI15, the 2015 version of the Parametric Catalogue of Italian Earthquakes. Istituto Nazionale di Geofisica e Vulcanologia. doi: http:/ / doi.org/10.6092/INGV.IT-CPTI15

[Saul et al., 2011] Saul, J., Becker, J., Hanka, W. (2011): Global moment tensor computation at GFZ Potsdam, AGU 2011 Fall Meeting (San Francisco 2011), http: / / gfzpublic.gfz-potsdam. de/pubman/item/escidoc:244630.

[Scognamiglio et al., 2009] Scognamiglio L., E. Tinti, and A. Michelini, (2009). Real-time determination of seismic moment tensor for italian region, Bull. Seism. Soc. of Am., 99:4, 22232242, doi:10.1785/0120080104.

[Vallée et al., 2011] Vallée, M., J. Charléty, A.M.G. Ferreira, B. Delouis, and J. Vergoz, SCARDEC : a new technique for the rapid determination of seismic moment magnitude, focal mechanism and source time functions for large earthquakes using body wave deconvolution, Geophys. J. Int., 184, 338-358, 2011. 